\title{
Standardized bioassays: An improved method for studying Fusarium oxysporum f. sp. cubense race 4 (FocR4) pathogen stress response in Musa acuminata cv. 'Berangan'
}

\author{
Yusmin Mohd-Yusuf a,c, Norzulaani Khalid ${ }^{\mathrm{c}, \mathrm{d}}$, Jameel R. Al-Obaidi ${ }^{\mathrm{b}}$, Nadiya Akmal Baharum, ${ }^{\mathrm{c}, \mathrm{e}, e^{*} \text {, }}$ \\ Kamilatulhusna Zaidic, ${ }^{\mathrm{c}}$, Baharuddin Salleh ${ }^{\mathrm{g}}$, Nurul Farizah Azuddin' ${ }^{\mathrm{g}}$, Fashli Aziz Abdul Aziz ${ }^{\mathrm{c}, \mathrm{d}}$, Umaiyal \\ Munusamy $y^{c, f}$, Rofina Yasmin Othman ${ }^{c, d^{*}}$ \\ ${ }^{a}$ Centre for Foundation Studies in Science, University of Malaya, 50603 Kuala Lumpur, Malaysia \\ bAgro-biotechnology Institute Malaysia (ABI), National Institutes of Biotechnology Malaysia, c/ o MARDI Headquarters, 43400 Serdang, \\ Selangor, Malaysia \\ 'Centre for Research in Biotechnology for Agriculture (CEBAR), University of Malaya, 50603 Kuala Lumpur, Malaysia \\ 'Institute of Biological Sciences, Faculty of Science, University of Malaya, 50603 Kuala Lumpur, Malaysia \\ eDepartment of Cell and Molecular Biology, Faculty of Biotechnology and Biomolecular Sciences, Universiti Putra Malaysia, 43400 UPM \\ Serdang, Selangor, Malaysia \\ Institute of Plantation Studies, Universiti Putra Malaysia, 43400 UPM Serdang, Selangor, Malaysia \\ ${ }^{g}$ School of Biological Sciences, Universiti Sains Malaysia, 11800 Penang, Malaysia
}

Received 19th November 2018 / Accepted 13th July 2019

\begin{abstract}
To date, there is no standardized Fusarium bioassay protocol established owing partly to the wide variety of Fusarium oxysporum $\mathrm{f}$. sp. cubense (Foc) isolates and banana cultivars present. Thus, validation of the infection parameters is deemed essential prior to each bioassay experiment. In the current study, a simple standardized workflow was developed based on available assays for testing Fusarium wilt disease response in Musa acuminata using M. acuminata cv. 'Berangan' of tissue-culture origin as a model. The phenotypic assays were able to detect external disease symptoms less than one week post-inoculation, while the molecular approach using RT-qPCR identified differential expression of catalase (CAT), pathogenesis-related 10 (PR10), phenylalanine ammonia-lyase (PAL) and xylanase (XYL) genes as early as day 0. The transcript levels of PR10 and XYL fluctuated over 4 days of Foc Race 4 (FocR4 C1 HIR isolate) infection while the expression of $C A T$ steadily increased over time. In contrast, $P A L$ was highly upregulated at 2 days post-inoculation. These signature changes suggest that all genes tested might be involved in the early defense response of 'Berangan' plants against FocR4 infection. 'Berangan' cultivar was found to be highly susceptible to Foc Race 4 (C1 HIR isolate) with leaf symptoms index (LSI) and rhizome discoloration index (RDI) scores of 4.257 and 5.971, respectively. The procedure elaborated in this study can be used as a reference Foc bioassay for reproducible and comparable results possibly across cultivars and test isolates due to its simple steps aided by integration of phenotypic and molecular approach.
\end{abstract}

Keywords: banana, Foc bioassay, Fusarium oxysporum f. sp. cubense, Fusarium wilt, Musa acuminata cv. 'Berangan', plant microbe interaction

\section{INTRODUCTION}

Fusarium wilt, caused by Fusarium oxysporum f. sp. cubense (Foc), is one of the most threatening fungal diseases affecting the banana production worldwide. The complexity of the Foc pathogen

*Author for correspondence: Rofina Yasmin Othman, email - yasmin@um. edu.my; Nadiya Akmal Baharum, email - nadiya_baharum@upm.edu.my 
which can manifest into different subtypes or races has resulted in global Fusarium outbreaks as reported in Latin America, the Carribean Islands, Taiwan, the Philippines, Malaysia, Indonesia and China (Subramaniam et al., 2006; Thangavelu et al., 2012; IPPC 2013; García-Bastidas et al., 2014; Ortiz and Swennen 2014). Of these, Foc Tropical Race 4 (FocTR4) is considered as the most menacing subtype as it can infect a wide array of banana cultivars without any predisposing situation (Ploetz 2006; Ploetz 2015). The occurrence of FocTR 4 pathogen was previously limited to the tropical regions of Asia but has now been diagnosed in Oman, Jordan, Mozambique, Pakistan, Lebanon and more recently in Northern Queensland indicating that the disease is currently emerging in new regions of the world (Butler 2013; Ordoñez et al., 2015; O’neill et al., 2016)

Numerous management strategies such as soil treatments, crop rotation and fumigation have been employed to reduce the severity of the disease, but none is able to provide long-term sustainable control (Pegg et al., 1996; Thangavelu et al., 2012). The cultivation of tolerant/resistant varieties remains the most effective approach despite the arduous development and selection process (Hu et al., 2013; Ghag et al., 2014; Baharum et al., 2018). Recent reports on genomic approaches in understanding the interactions between Foc and banana have begun to shed light into the possibilities of exploring new strategies for the continued development of resistant varieties. This includes structural genomics (Michelmore 2000; Li et al., 2010), comparative genomics (Schmutz et al., 2014), functional genomics (Li et al., 2013) and genome wide association (Pasam et al., 2012).

The escalation of information on genome level studies is as much a result of the accessibility as well as the decreasing costs of analysis of highthroughput sequencing (or next-generation sequencing - NGS) technologies systems. Advances in genome wide analysis and the availability of the whole genome sequence of Foc and banana have certainly rekindled interest in Foc challenge experiments to study the interactions between Foc pathogens and various banana hosts (Mak et al., 2001; Paul et al., 2011; Ghag et al., 2014; Guo et al., 2014).

What was most apparent while reviewing these different studies was that no standardized bioassay protocols were used across the experiments which could probably be attributed to the vast number of banana cultivars and Foc isolates exist. Each experiment showed variation mostly in terms of inoculum concentrations, plant age, inoculation methods and disease scoring index (Mak et al., 2001; Paul et al., 2011; Li et al., 2012; Mahdavi et al., 2012). Furthermore, most experiments relied solely on the phenotypic observation which could lead to false positive or false negative results. Therefore, establishment of a standardized assay would help to ensure consistent infection conditions and expedite the comparative analysis of the resulting data. This would be particularly true for the assessment of transgenic lines and the development of standardized risk assessment protocols (Paul et al., 2011; Ghag et al., 2012; Mahdavi et al., 2012) that would facilitate regulatory approval and biosafety clearance. By incorporating both the phenotypic and molecular methods, this report presents a standardized procedure for testing Fusarium wilt disease response in Musa acuminata using $M$. acuminata cv. 'Berangan' of tissue-culture origin as a model.

\section{MATERIALS AND METHODS}

Plant material. Tissue culture-derived banana $M$. acuminata cv. 'Berangan' plantlets were obtained from CEBAR University of Malaya, Malaysia. Plantlets were maintained in Murashige and Skoog (MS) medium for 1 month. For rooting, MS active charcoal $(10 \mathrm{~g} / \mathrm{L})$ was used (Gübbük and Pekmezci 2004). Healthy plants of 2 months age with at least 3-5 green leaves, a minimum length of $5.0 \mathrm{~cm}$ of white roots and stem diameters of between 0.5 to $1.0 \mathrm{~cm}$ were chosen for infection studies (Figure 1).

Fungal isolates. FocR4 was provided by Prof. Dr. Baharuddin Salleh and was maintained as pure culture on potato dextrose agar (PDA) (Difco ${ }^{\mathrm{TM}}$, $\mathrm{BD}$, France) at the PhytoMycology Laboratory, University of Malaya and designated as isolate C1 HIR. The fungus was originally isolated from the inner stem of an infected $M$. acuminata cv. 'Cavendish' in Kuala Terengganu, Terengganu, Malaysia. 


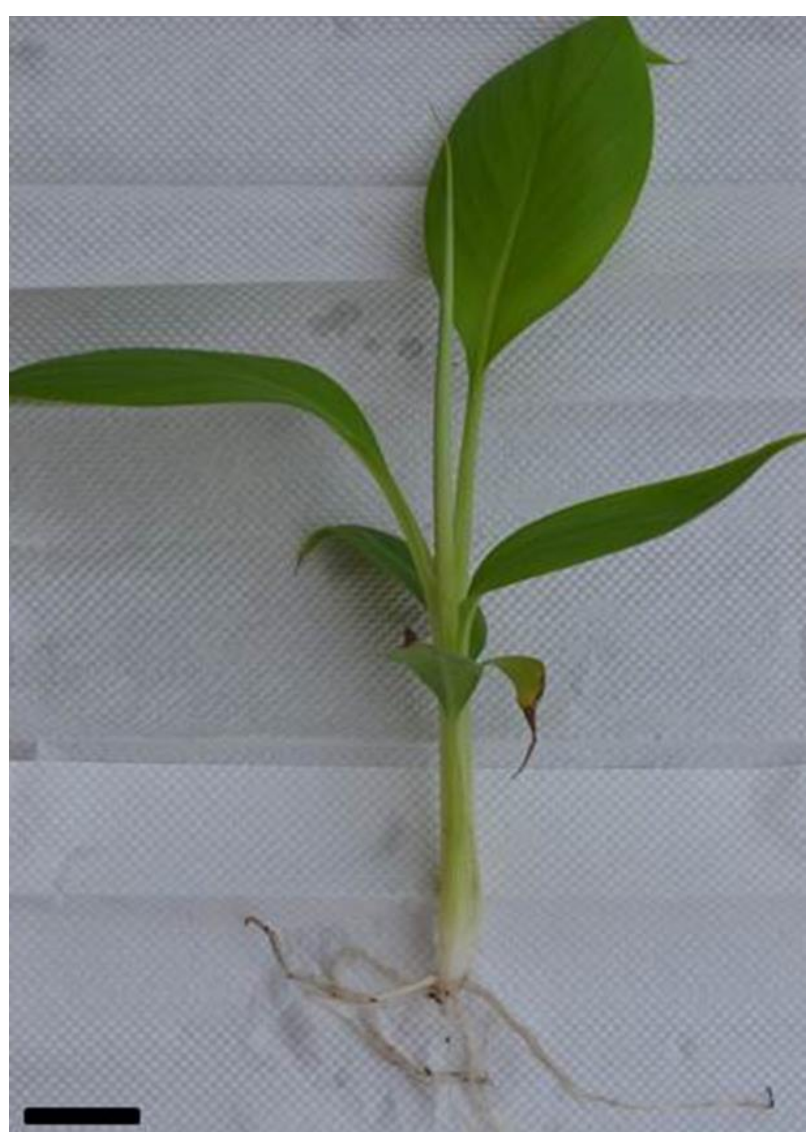

Figure 1. 2-month-old healthy Musa acuminata cv. 'Berangan' plant for bioassay study. Bar represents $3 \mathrm{~cm}$.

Single spore isolation and induction of sporulation. The working area was maintained under aseptic conditions throughout the induction process to obtain pure culture. Figure S1 illustrates the schematic procedure used. Pure culture was produced by single spore isolation through a standard streak plate procedure.

\section{Preparation of spore suspension culture and} viability test. Spore suspensions cultures of $\mathrm{C} 1$ HIR isolate were prepared by inoculating one loopful of mycelia previously incubated on PDA into $1 \mathrm{~L}$ of potato dextrose broth (PDB) (Difco ${ }^{\mathrm{TM}}$, $\mathrm{BD}$, France). The culture was incubated at room temperature $\left(25-27^{\circ} \mathrm{C}\right)$ and swirled twice a day. Viability was confirmed on the $5^{\text {th }}$ day postinoculation by scraping one loopful of incubated mycelia and mixed with $100 \mu \mathrm{L}$ of sterile distilled water. One loopful of the spore suspension prepared was streaked onto a PDA plate through a standard streak plate procedure. The plate was incubated at room temperature in the dark for 3648 hours to germinate the spores. The spore concentration was determined on the $7^{\text {th }}$ day postinoculation using a haemocytometer. Using $\mathrm{M}_{1} \mathrm{~V}_{1}=\mathrm{M}_{2} \mathrm{~V}_{2}$ formula, the inoculated spore culture was diluted using sterile distilled water to obtain a final concentration of $1 \times 10^{6}$ spores $/ \mathrm{mL}$.

Fusarium wilt bioassay. The Fusarium wilt bioassay protocols were adopted from protocols developed in our laboratory by $\mathrm{Mak}$ and coworkers (2001). Rooted plants were potted in 12 $\mathrm{cm} \times 9 \mathrm{~cm}$ pot containing 3:1 sterilized soil and sand respectively. Acclimatization was carried out in the greenhouse at ambient temperature (28$30^{\circ} \mathrm{C}$ ) with a 16 -hour photoperiod. After 60 days of acclimatization, a total of 35 plants which fulfilled the criteria as mentioned in section 2.1 were carefully uprooted for Foc C1 HIR inoculation. Prior to inoculation, the roots were rinsed with tap water to remove any soil residue before the whole-root was immersed for two hours in the C1 HIR conidial suspension. The infected plants were then re-planted into the original soil with appropriate labels. The plants were transferred to a double-container apparatus and maintained in the greenhouse under the same conditions (Figure S2). The double compartment consists of a tray measuring $43 \times 29 \times 9 \mathrm{~cm}$, which fits snugly into another, larger, outer tray measuring $46 \times 31 \times 20 \mathrm{~cm}$ (Figure S3). The plants were watered with tap water every other day and with Hoagland solution (Sigma-Aldrich, U.S.A.) once a week. The number of leaves showing yellowing and wilting symptoms was recorded in the $2^{\text {nd }}$ and $4^{\text {th }}$ week before the final disease score was determined at the end of the $5^{\text {th }}$ week postinoculation. Sterile distilled water was used as 'inoculum' for the negative control plants.

\section{Scoring of leaf symptoms index (LSI) and rhizome discoloration index (RDI). The} severity of C1 HIR infection on 'Berangan' plants was determined using the protocols modified from Mak et al., (2001). At the end of the $5^{\text {th }}$ weekpost-inoculation, the number of leaves showing yellowing and wilting symptoms was recorded. The infected plants were carefully uprooted and their rhizomes were vertically cut into half to observe the brownish/darkish discoloration. The response on the leaves and rhizomes against $\mathrm{C} 1$ HIR infection was determined based on the leaf symptoms index (LSI) and rhizome discoloration 
index (RDI), respectively (Table S1). Reference diagrams showing different degrees of infection on the leaves and rhizome with respective LSI and RDI scores were compiled to assist the evaluation process (Figure S4). The scores were then used to calculate the disease severity index (DSI) for each LSI and RDI, separately. The formula for DSI is as shown below.

$D S I=\sum$ (Number on scale $x$ Number of seedlings in that scale) $\Sigma$ (Number of treated seedlings)

The final DSI value of the test cultivar is correlated with one of the four designations (Table S2). In the case when one of the indexes is designated as susceptible, the cultivar is regarded as susceptible against that particular isolate. Similarly, if one of the scores (either LSI or RDI) is indicated as tolerant while the other as resistant, then the cultivar is considered as tolerant. When both disease indications are resistant, only then the cultivar will be considered as resistant.

The scoring methods used in this study established distinct scales for each leaf symptoms index (LSI) and rhizome discoloration index (RDI). The DSI values calculated from each LSI and RDI would be translated based on the standardized range to eventually determine the susceptibility or resistance level of the infected variety against test isolate. By correlating both external and internal scores, the observation would be less prone to bias allowing an impartial final disease evaluation.

\section{Molecular analysis.}

C1 HIR verification using FocR4-specific primers.

DNA extraction of Foc C1 HIR was performed using a modified CTAB method described by Lin et al., (2009). PCR amplifications were carried out using Foc race 4 specific primers (Table 1) (Lin et al., 2009). Amplifications were performed in a total volume reaction of $20 \mu \mathrm{L}$ containing $10 \mu \mathrm{L}$ of $2 \mathrm{x}$ Phusion Flash PCR Master Mix (Thermo Fisher Scientific, U.S.A.), $0.5 \mu \mathrm{M}$ of both primers, $1 \mu \mathrm{L}$ of DNA (10 ng) and nuclease-free water. Reactions were carried out in a ThermoScientific Thermal Cycler with the following conditions: Initial denaturation at $98^{\circ} \mathrm{C}$ for $10 \mathrm{~s}$, followed by 34 cycles of second denaturation at $98^{\circ} \mathrm{C}$ for $1 \mathrm{~s}$, annealing stage at $68^{\circ} \mathrm{C}$ for $30 \mathrm{~s}$, extension at $72^{\circ} \mathrm{C}$ for $15 \mathrm{~s}$ and a final extension step at $72^{\circ} \mathrm{C}$ for 1 min. The amplified PCR product was analyzed by
$1 \%$ agarose gel electrophoresis at $100 \mathrm{~V}$ for 30 min. The targeted amplified product was sequenced using BigDye ${ }^{\circledR}$ Terminator v3.1 Cycle Sequencing Kit in an ABI PRISM 3730xl Genetic Analyzer (Applied Biosystems, U.S.A.). The BLASTn and BLASTp programs (https://blast. ncbi.nlm.nih.gov/Blast.cgi) were used for gene sequence similarity search.

$R N A$ extraction and $c D N A$ synthesis.

Total RNA was extracted from infected and noninfected roots at 0-, 2- and 4-day post-inoculation (dpi) using RNeasy ${ }^{\circledR}$ Plant Mini Kits, (Qiagen, Germany) according to the manufacturer's instructions. RNA quality was evaluated using an Agilent 2100 Bioanalyzer with a minimum integrity number value of eight. The quantity and quality of the RNA obtained were also assessed using NanoDrop 2000 Spectrophotometer (ThermoScientific, U.S.A.). The $\mathrm{A}_{260 / 280}$ ratio was used to detect protein contamination and the $\mathrm{A}_{260 / 230}$ ratio was used to determine carbohydrate contamination. The integrity of the isolated RNA was also verified by electrophoresing RNA on 1.5 $\%$ agarose gel and staining with ethidium bromide. The bands were visualized and photographed using an Alpha Innotech AlphaImager ${ }^{\text {TM }} 2200$ UV Gel Video Image Analysis System. The cDNA was synthesized using TransScript One-Step gDNA removal and cDNA synthesis SuperMix kit (TransGen Biotech, China) as recommended by the manufacturer.

\section{Primer designing and RT-qPCR conditions.}

Catalase (CAT), pathogenesis-related 10 (PR10), phenylalanine ammonia lyase $(P A L)$ and xylanase (XYL) genes were selected as standards to assay the expression profile of disease response genes. The primers of three housekeeping genes namely $40 S$ ribosomal protein S2 (RPS2), ubiquitin (UBQ) and glyceraldebyde-3-phosphate $(G A P D H)$ were also designed. All primers were designed by using Primer 3 software and listed in Table 1.

Determination of the gene expression stability of the three reference genes (RPS2, UBQ2R and $G A P D H$ genes) in non-treated and treated root samples was carried out using NormFinder (Andersen et al., 2004) as previously reported (Munusamy et al., 2019a). The real-time expression profiles of $C A T, P R 10, P A L$ and $X Y L$ 
were analyzed in cDNA samples obtained from both infected and non-infected banana roots. Real-time analysis was performed in an Applied Biosystem 7500 Fast Real Time System using KAFA SYBR FAST qPCR Kit Master Mix (2X) Universal (Merck, U.S.A.). A total of $20 \mu \mathrm{L}$ reaction mixture consisted of $1 \mu \mathrm{L}$ of cDNA sample, $10 \mu \mathrm{L}$ of KAPA SYBR FAST qPCR Master Mix (2x) Universal, $0.4 \mu \mathrm{L}$ of forward and reverse real time primers and $0.4 \mu \mathrm{L}$ ROX low was prepared. Non-template reaction (NTC) contained nuclease free water instead of cDNA as template. Amplification cycles were as follows: Initial denaturation at $95^{\circ} \mathrm{C}$ for $10 \mathrm{~min}$, followed by 40 cycles of amplification at $92^{\circ} \mathrm{C}$ for $15 \mathrm{~s}$, and $60^{\circ} \mathrm{C}$ for $120 \mathrm{~s}$ with the fluorescence being read at the end of each cycle. Dissociation curve was generated to evaluate the presence of non-specific PCR products and primer dimers.

Table 1. List of primers.

\begin{tabular}{cccc}
\hline Primer name & $\mathbf{T}_{\mathbf{m}}{ }^{\circ} \mathbf{C}$ & Nucleotide sequence 5' to 3' & Applications \\
\hline FOC4F* & 51.2 & CAGGGGATGTATGAGGAGGCT & PCR \\
FOC4R* & 51.2 & GTGACAGCGTCGTCTAGTTCC & PCR \\
Pr10F & 49.2 & CTCCGAGAAGCAGTACTACGA & qPCR \\
Pr10R & 43.3 & GATGGCCGTGGACGAA & qPCR \\
PALF & 48.7 & ACAGGAGGACCAAGCAAGGA & qPCR \\
PALR & 47.5 & CGTCCCGGAGCCGAATAT & qPCR \\
CatF & 49.2 & AAGGTCTCACCGCTTGTCTCA & qPCR \\
CatR & 48.1 & CGTCGCGGATGAAGAACAC & qPCR \\
XylF & 43.9 & GCGCCGGCGGTGAT & qPCR \\
XylR & 48.7 & GATAAACCCGAGCCGCTTCT & qPCR \\
RPS2F & 46.0 & TAGGGATTCCGACGATTTGTTT & qPCR \\
RPS2R & 49.2 & TAGCGTCATCATTGGCTGGGA & qPCR \\
UBQ2F & 48.7 & GGCACCACAAACAACACAGG & qPCR \\
UBQ2R & 46.7 & AGACGAGCAAGGCTTCCATT & qPCR \\
GAPDHF: & 52.3 & ACCACAAATTGCCTTGCTCCCTTG & qPCR \\
GAPDHF: & 52.3 & ATCAACGGTCTTCTGAGTGGCTGT & qPCR \\
\hline
\end{tabular}

** All primers were designed by using Primer3 software (Munusamy et al., 2019a) except for FOC4F* and FOC4R* that was adapted from Lin et al., (2009).

Data analysis. Relative expression levels were calculated from the Ct value using the formula: $2^{\Delta \Delta \mathrm{Ct}}$ derived from the Pfaffl method (Pfaffl 2004). All triplicate data were subjected to statistical analysis. The data presented herein were the average results of the experiments and all data were subjected to normality test. One-way analysis of variance (ANOVA) was performed for all raw data using Duncan multiple range tests. All analyses were performed at the level of $5 \%$ using SPSS software packages (SPSS Inc., IL, U.S.A).

\section{RESULTS}

Verification of Foc C1 HIR race group and fungal inoculation. After 4-5 days of incubation in the dark at room temperature, extensive white purplish mycelium indicating germinated spores of C1 HIR was observed on PDA (Figure 2).

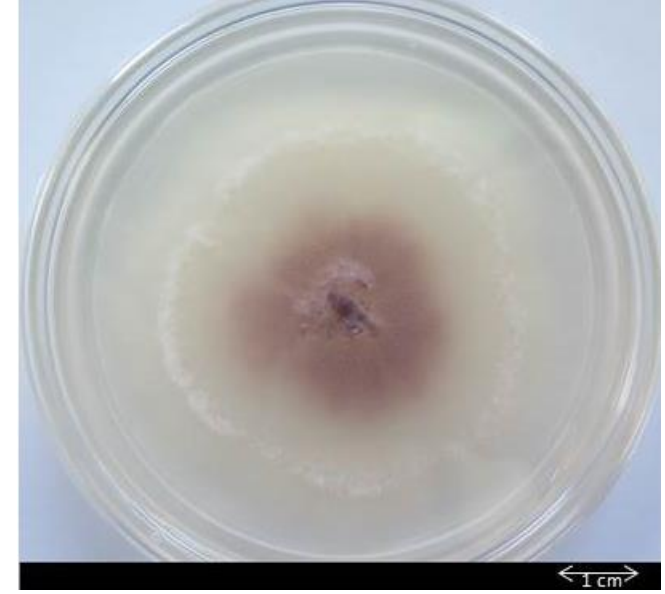

Figure 2. White purplish FocR4 (C1 HIR) mycelium growth on PDA. Bar represents $1 \mathrm{~cm}$. PDB inoculated with the mycelium became turbid and showed significant mycelium growth after 57 days of incubation. The 5-day-old Foc suspension culture successfully germinated after at least 48 hours of incubation on PDA. This 
confirmed the viability of the fungal suspension that would be used in the bioassay experiments.

\section{Plant disease response.}

\section{LSI, RDI and DSI.}

Wild-type 'Berangan' plants infected with C1 HIR demonstrated disease symptoms less than one week-post-inoculation. Externally, lower leaves of the infected plants showed streaking and yellowing symptoms which later progressed to the midrib area (Figure 3A). More severe infection was noted when most or all of the leaves exhibited yellowing and wilting symptoms. Completely wilted leaves eventually abscised the petiole and led to plant's death (Figure 3B). Uninfected plants remained healthy throughout the bioassay experiment (Figure 3C).
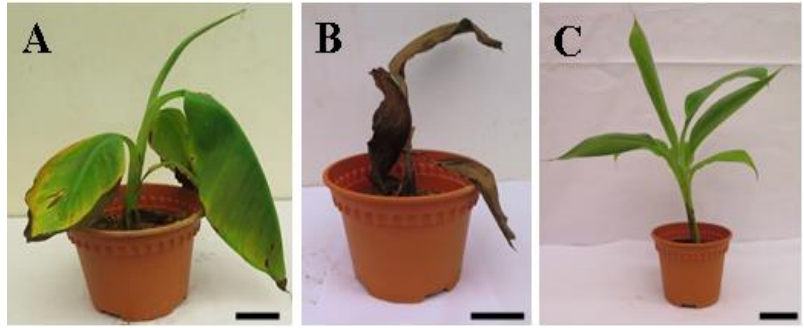

Figure 3. Representatives of C1 HIR-inoculated (A \& B) and non-inoculated (C) 2-month-old wild-type 'Berangan' plants for leaf symptoms. Plant A showed typical yellowing symptoms on the leaves as early as 6 days post-inoculation (dpi). As the disease progresses, more severe wilting symptoms that lead to plant's death (B) were observed at the end of the $5^{\text {th }}$ week postinoculation due to the advanced hyphae colonization of the vascular tissue. Noninoculated plantlet (C) remained healthy throughout the bioassay experiment. Bar represents $5 \mathrm{~cm}$.

Internally, plants with less severe symptom displayed brownish to darkish discoloration at the junction of root and rhizome (Figure 4A). As hyphae advanced and colonized the vascular tissues, more discoloration was discovered especially in the stele region of the rhizome indicating a more severe disease incidence and ultimately contributed to the plant's death (Figure 4B). Rhizomes of uninfected plants showed no discoloration symptom (Figure 4C). In the final disease scoring performed in the $5^{\text {th }}$ week, $M$. acuminata cv. 'Berangan' was found to be highly susceptible to FocR4 (C1 HIR) isolate with LSI and RDI scores of 4.257 and 5.971, respectively (Table S3).
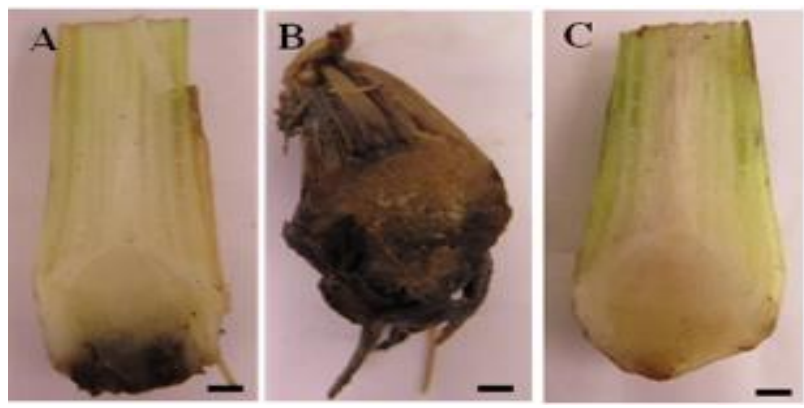

Figure 4. Representatives of C1 HIR-inoculated (A \& B) and non-inoculated (C) 2-month-old wild-type 'Berangan' plants for rhizome symptoms. Rhizomes of infected plants showed various degrees of discoloration that may start from the junction of root and rhizome (A) as early as 6-dpi advancing to the pseudostem and eventually led to the plant's death (B) at the end of the $5^{\text {th }}$ week post-inoculation. Rhizome of noninoculated wild-type 'Berangan' (C) remained healthy throughout the bioassay experiment. Bar represents $0.5 \mathrm{~cm}$

Molecular detection of C1 HIR using FocR4 specific primers in inoculated plants.

C1 HIR was classified as a race 4 isolate based on the presence of a 242-bp band upon amplification using specific FOC4F and FOC4R primer pair (Figure 5). The sequences of the fragments showed $99 \%$ similarity to Fusarium oxysporum (EF155535.1 and KF270878.1) (Figure S5 and Fig. S6).

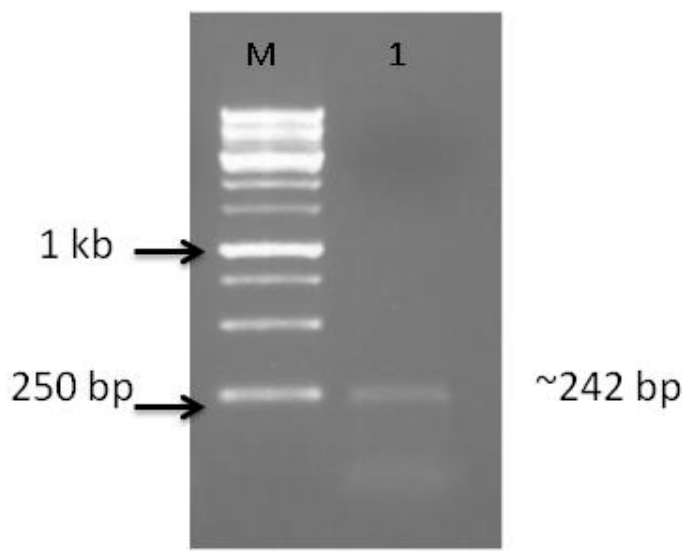

Figure 5. PCR analysis of FocR4 CI HIR isolate. The presence of the 242-bp band showed the positive amplification of FocR4. Lane M: GeneRuler $^{\text {TM }} 1$ kb DNA Ladder; Lane 1: C1 HIR isolate. 
$\mathrm{RN} A$ quality.

The $A_{260} / A_{280}$ ratios of the RNA extracts were in the range of 1.8-2.0. All RNA samples have a RIN value above 6.0 (Fig. 6). The coefficient of variation $(\mathrm{CV})$ of the RIN measurements were in the range of $0 \%$ to $3 \%$. The quality of the extracted RNA was considered sufficient for obtaining consistent and reproducible gene expression data (Rosas-Cárdenas et al., 2011).
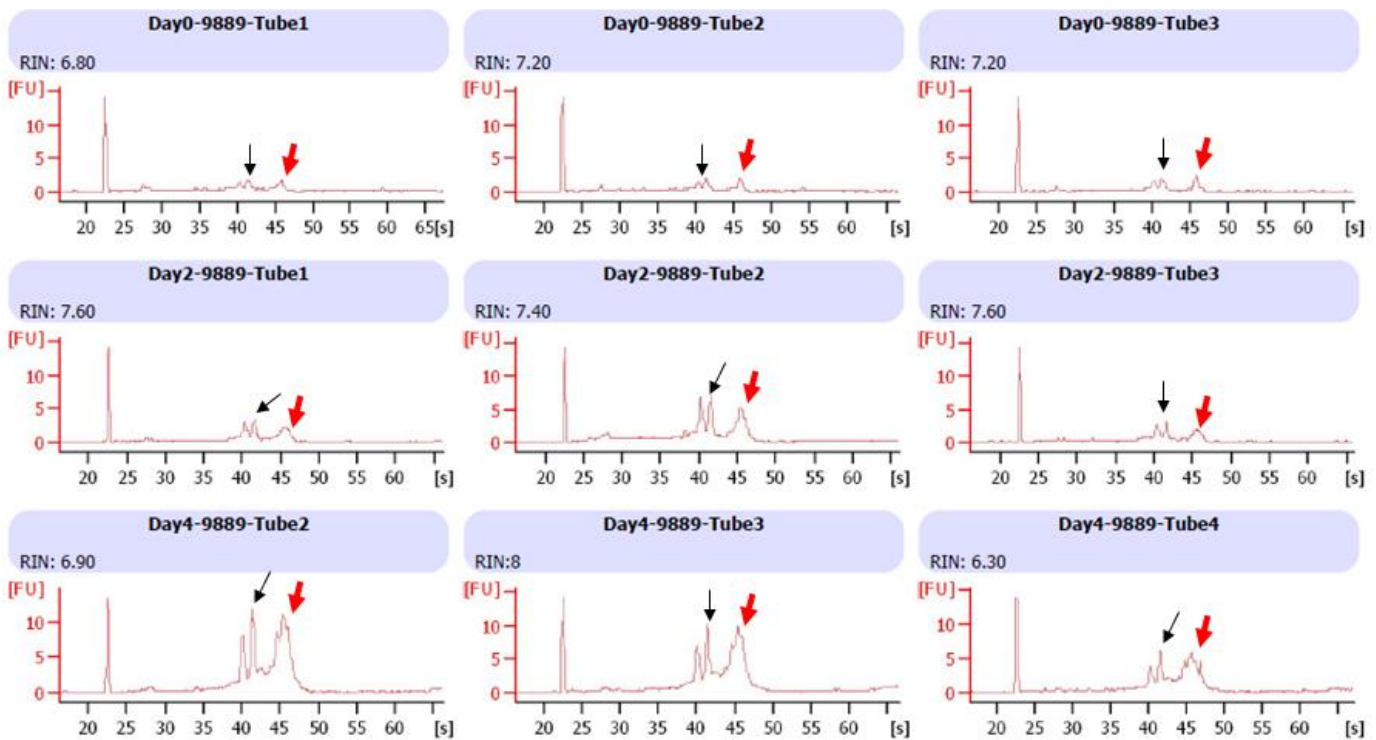

Figure 6. Electropherograms detailing the regions for $18 \mathrm{~S}(\mathbf{4})$ and $28 \mathrm{~S}$ (4) of the extracted RNA samples from root tissue of banana cv. 'Berangan' infected with FocR4 C1 HIR (labelled as 9889) at day 0-, 2- and 4-day old with RIN ranging from 6.8 to 8.0.

Real time analysis of disease response genes.

CAT, PAL, PR10 and XYL demonstrated differential expression within 4 days of FocR4 infection when normalized against RPS2 gene (Figure 7). The expression levels of CAT steadily increased over time while the transcript levels of PR10 and XYL decreased at 2 dpi and escalated later at $4 \mathrm{dpi}$. In contrast, the expression level of $P A L$ peaked at $2 \mathrm{dpi}$ before it decreased afterwards (Table 2).

\section{DISCUSSION}

The continuing threat of Fusarium wilt on banana cultivation has resulted in attempts to control the disease that has met with limited success. The proliferation of reports assessing the Foc-banana interactions using next-generation molecular tools has highlighted the need for a standardized bioassay procedure to assess the performance of existing and new varieties of banana towards Fusarium infection. Thus, the present study discusses important parameters of a standardized bioassay for Fusarium infection using $M$. acuminata cv. 'Berangan' as a model.

Inoculation procedure. A standard pure culture inoculum (C1 HIR isolate) with a validated infection profile on banana plants is used in our laboratory for all challenge experiments. For each assay, a simple and reproducible PCR protocol using specific FocR 4 primers was performed to validate the race group of C1 HIR isolate (Lin et al., 2009). The PCR-based assays have been reported to successfully identify and characterize Foc (Muhammad and Othman 2005; Lin et al., 2009, 2010; Durai et al., 2012; Mishra et al., 2013; Scarlett et al., 2013) as well as other Fusarium species such as Fusarium oxysporum f. sp. chrysanthemi (Li et al., 2010). The PCR-based identification of Foc race 4 has also been performed by Li et al., (2013) and Dita et al., (2010) using a different set of primers. Li and co-workers (2013) amplified a unique DNA fragment of approximately 364 bp using Foc primers identified as Foc-F/Foc-R while Dita et al., (2010) amplified 563 bp amplicon by using FocTR4-F/ Foc'TR4-R primer set. Both of them produced 
bigger amplicon compared to the method by Lin and co-workers (2009). The method from Lin and co-workers (2009) was chosen because amplification of smaller amplicon was easier to amplify, fast, and efficient.

Table 2. Expression levels of PR10, CAT, PAL and XYL at 0-, 2- and 4-dpi determined using qPCR. All data were subject to one-way ANOVA.

\begin{tabular}{ccccc}
\hline $\begin{array}{c}\text { Day post- } \\
\text { inoculation } \\
\text { (dpi) }\end{array}$ & $\boldsymbol{P R 1 0}$ & $\boldsymbol{C A T}$ & $\boldsymbol{P A L}$ & $\boldsymbol{X Y L}$ \\
\hline 0 & $7.11 \pm 1.62 \mathrm{a}$ & $0.40 \pm 0.08 \mathrm{c}$ & $2.83 \pm 0.69 \mathrm{e}$ & $1.60 \pm 1.49 \mathrm{~g}$ \\
2 & $2.30 \pm 0.18 \mathrm{~b}$ & $1.00 \pm 0.52 \mathrm{c}$ & $13.83 \pm 9.22 \mathrm{f}$ & $0.37 \pm 0.39 \mathrm{~g}$ \\
4 & $3.75 \pm 1.07 \mathrm{~b}$ & $2.23 \pm 0.61 \mathrm{~d}$ & $8.59 \pm 2.91 \mathrm{ef}$ & $1.57 \pm 1.07 \mathrm{~g}$ \\
\hline
\end{tabular}

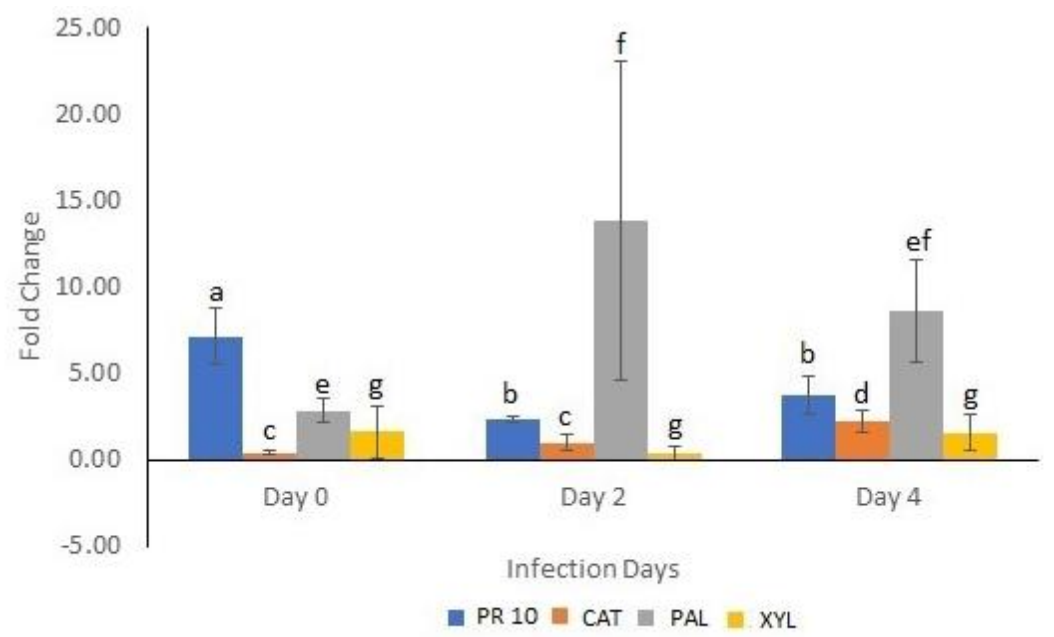

Figure 7. Expression levels of the selected pathogen responsive genes by qPCR. The bars represent the fold changes of the expression levels. All data were subject to one-way ANOVA. The data shown are expressed as the mean (\%) of three replicates \pm SE from three representative experiments. SE indicates standard error bar; same letter denotes not significant $(\mathrm{p} \geq 0.05)$ by Duncan test.

As for the inoculum concentration, a range of spore concentrations from $10^{4}$ to $10^{6}$ spore $/ \mathrm{mL}$ have been applied in various reported studies (Paul et al., 2011; Guo et al., 2014; Pérez Vicente et al., 2014). It was shown previously that lower inoculum concentrations were inconsistent and may not elicit reproducible phenotypic symptoms as indicated by the DSI scores (Mak et al., 2001; Javed et al., 2004). Conidial concentration at $10^{6}$ spores $/ \mathrm{mL}$ is recommended for all bioassays as it was found to be optimal for eliciting consistent symptom progression that is typical for Fusarium wilt disease. In general, the concentration of spores used in any challenge program should be consistent to ensure similar surface area to volume ratio for inoculum contact as variations may affect the plant responses as well as the gene expression profiles in the subsequent studies
(Pérez Vicente et al., 2014). In relation to this, unsuitable growth substrates and conditions may also gradually decrease the Foc growth. Hence, it is necessary to produce the inoculum using appropriate growth medium under defined incubation conditions.

A steadfast infection assay should be able to mimic the natural mode of plant-pathogen exposure. As for Foc, this would typically be through the root contact. The root dipping technique is preferred as it is simple and reliable. Plants at two months old are easy to handle and damage to the roots can be minimized during the procedure. Masheva and Todorova (2013) speculated that root dipping method that was applied in strawberry and pepper plants is able to facilitate direct contact between their roots and inoculum. They found that the index of 
infestation was higher when using root dipping technique compared to that recorded in noninfected plant materials planted in infected soil. Another common technique used in Foc bioassay was inoculation of planting medium with the test isolate. While it is agreeable that this technique more similarly mimics the natural infection condition, the growth and reproduction rate of the spores in each potting mixture cannot be fully monitored which may affect the degree of infection. Thus, choosing a suitable inoculation procedure that would minimize other unexpected parameters is essential to avoid false-positive results. Another important parameter to be considered is the duration of inoculation. For FocR4, an exposure time of two hours consistently produced the expected disease progression in susceptible 'Berangan' cultivars. This was in concordance with the previous reports of Foc infection on different banana cultivars (Paul et al., 2011; Guo et al., 2014). On the other hand, Pérez Vicente et al., (2014) suggested that a 30-minute of inoculum contact was sufficient to initiate Foc infection. Similarly, Mahdavi et al., (2012) used a one-hour of inoculation period with additional application Foc suspension to assess the disease response of transgenic $M$. sapientum cv. 'Nangka' following FocTR4 infection.

\section{Validation of disease progression.} Conventionally, observation on the external (yellowing and wilting of leaves) and internal symptoms (rhizome discoloration) were used as a standard for evaluation. A number of protocols distinguished both external and internal scoring systems (Javed et al., 2004; Paul et al., 2011). Since the external and internal scales are often not associated with each other, inconsistent results have been observed. For instance, infected plants may have fairly good rhizome discoloration score while displaying severe yellowing symptoms probably caused by external factors such as nutrient deficiency or unfavorable growth parameters (Czembor et al., 2015). To address this problem, the present study correlates both the external and internal observation to establish a reliable disease scoring scale.

In addition to disease rating scale, the expression analysis of standard disease response genes was also proposed to support the validation of progressive Foc infection. The incorporation of molecular analysis via specific gene expression analysis assists in the evaluation of disease progression and is particularly useful when comparing large data sets from different experiments or between laboratories. Four defense-related genes (CAT, PR10, PAL and $X Y L)$ used in this experiment were selected based on the in-vivo analysis of our transcriptome data deposited in NCBI database (Accession No: SAMN03793159 to SAMN03793167) and their involvement in the defense mechanism, particularly during the early stages of general pathogen infection (Blackman and Hardham 2008; Zhang et al., 2010; Kim et al., 2016; Munusamy et al., 2019b). During pathogen attack, extracellular, membrane-embedded pathogen recognition receptors (PRR) recognizes the pathogen-associated molecular patterns (PAMPs) released by the pathogen which leads to activation of MAMP-triggered immunity (MTI). As a result, various downstream defense responses were triggered which include physical modification of the host's cell wall, release of defense-related genes such as pathogenesis-related (PR) genes, production of reactive oxygen species (ROS), various signal transduction pathways and secondary metabolites (Dodds and Rathjen 2010). PR10, in particular, is a member of PR proteins families. PR10 is speculated to possess ribonuclease activity due to its homologous structure with ginseng ribonuclease (Moiseyev et al., 1994). As a type of nuclease that degrades RNA into smaller components, RNase is able to inhibit translational activity and thus, protecting the plant cells from any harmful action induced by the pathogen. In addition to FocR4, PR10 was also responsive to other fungal attacks such as Rhizoctonia solani, Colletotrichum acutatum and Aspergillus flavus as reported in ginseng, pepper and maize, respectively (Chen et al., 2006; Soh et al., 2012; Kim et al., 2014).

Some of the downstream defense responses are closely associated with the phenylpropanoid pathway exist in plants. Lignin deposition, which is a form of cell wall modification, acts as a physical and chemical barrier protecting the plants from invading pathogens. One of the production mechanisms of lignin is through monolignol biosynthesis which is derived from phenylalanine via the phenylpropanoid pathway. This 
mechanism has been well-demonstrated in Arabidopsis (Xie et al., 2018). Being the first key enzyme in this pathway, $P A L$ plays an essential role in catalyzing the substrates to provide precursors for the downstream reactions (Fraser and Chapple 2011). Exposure to biotic stress has resulted in elevated expression of genes involved this pathway, including PAL (Giberti et al., 2012; Zhang et al., 2017). Besides lignin accumulation, phenylpropanoid pathway is also responsible for the synthesis of various other phenolics compounds. These include flavonoids, stilbenes and coumarins. Interestingly, many of these inducible secondary metabolites are phytoalexins, which are compounds that possess anti-microbial activities against a wide array of pathogens (König et al., 2014). Catalase, on the other hand, is an antioxidant enzyme which acts as ROS scavenger. Thus, up-regulated expression of anti-oxidant enzymes involve in ROS detoxification is expected to minimize the damage caused by toxic ROS on the host cell (Mittler et al., 2004). In this study, both $P A L$ and $C A T$ genes were upregulated within 96 hours of inoculation to engage in the early defense responses against the infection.

Similar results were reported by Van den Berg et al., (2007) in which the expression of CAT was enhanced in tolerant and susceptible Cavendish banana plantlet upon Foc subtropical race 4 infection. Catalase was also found to be upregulated at 72 -hour post-inoculation in resistant M. acuminata subsp burmannicoides Calcutta 4 following Mycosphaerella fijiensis infection (Rodriguez et al., 2016). In the same study, Rodriguez and his co-workers (2016) showed increased expression of $P A L$ gene following the same pathogen attack. Consistently, expression of $P A L$ in pepper leaves $(C a P A L 1)$ was also induced when instigated by avirulent Xanthomonas campestris pv. vesicatoria $(\mathrm{Xcv}) \mathrm{Bv} 5-4 \mathrm{a}$ (Kim and Hwang 2014). XYL on the other hand is known to induce host defence responses in certain host-pathogen pathosystems. During a successful invasion, most plant pathogens produce xylanase to degrade plant cell wall to enter plant cell environment (Siah et al., 2010).

Other considerations. Additionally, treatment of contaminated waste and materials including plants, trays and soil from the experiment was often not reported thus providing very little information on the sanitary procedures that should be followed. The introduction of 'double tray' method by Mak and co-workers (2001) provided a safe Foc challenge procedure. The protocols offer a controlled environment for testing the plants' response against the pathogen with minimal space requirement. In this set-up, contaminated water will be drained into the lower tray prior to the treatment with sodium hypochlorite. Portable trays can be easily washed with the same solution while all the plant materials and soil can be autoclaved before being discarded. Pérez Vicente and co-workers (2014) additionally suggested all the materials were to be autoclaved twice with a 24-hour interval as a part of poststerilization process.

\section{CONCLUSION}

In this study, a systematic bioassay procedure for testing FocR4 (C1 HIR) infection in $\mathrm{cv}$. 'Berangan' banana has been established. This standardized assay facilitates cross confirmation in quality control and assurance that can be carried out by independent laboratories. The findings were strengthened by assessing the phenotypic symptoms as well as the gene expression profiles in determining the overall disease progression.

\section{ACKNOWLEDGEMENTS}

This work was supported by grant (53-02-031068) financed by the Ministry of Science, Technology and Innovation (MOSTI) Malaysia; a University of Malaya Research Grant (RP005C13BIO) and a University Malaya High Impact Research Grant (UM.C/625/1/HIR/MOHE/ SCI/18).

\section{REFERENCES}

\footnotetext{
Andersen, C. L., Jensen, J. L., \& Ørntoft, T. F. 2004. Normalization of real-time quantitative reverse transcription-PCR data: a model-based variance estimation
} 
approach to identify genes suited for normalization, applied to bladder and colon cancer data sets. Cancer Research 64(15): 5245-5250.

Baharum, N. A., Othman, R. Y., Mohd-Yusuf, Y., Tan, B. C., Zaidi, K., \& Khalid, N. 2018. The effect of pathogenesisrelated 10 (PR-10) gene on the progression of Fusarium Wilt in Musa acuminata cv. Berangan. Sains Malaysiana 47(10): 2291-2300.

Blackman, L. M. \& Hardham, A. R. 2008. Regulation of catalase activity and gene expression during Phytophthora nicotianae development and infection of tobacco. Molecular Plant Pathology 9(4): 495-510.

Butler, D. 2013. Fungus threatens top banana. Nature 504(7479): 195.

Chen, Z.-Y., Brown, R., Rajasekaran, K., Damann, K., \& Cleveland, T. 2006. Identification of a maize kernel pathogenesis-related protein and evidence for its involvement in resistance to Aspergillus flavus infection and aflatoxin production. Phytopathology 96(1): 87-95.

Czembor, E., Stępień, L., \& Waśkiewicz, A. 2015. Effect of environmental factors on Fusarium species and associated mycotoxins in maize grain grown in Poland. PloS one 10(7): $\mathrm{e} 0133644$.

Dita, M. A., Waalwijk, C., Buddenhagen, I. W., Souza Jr, M. T., \& Kema, G. H. J. 2010. A molecular diagnostic for tropical race 4 of the banana Fusarium wilt pathogen. Plant Pathology 59(2): 348-357.

Dodds, P. N. \& Rathjen, J. P. 2010. Plant immunity: towards an integrated view of plant-pathogen interactions. Nature Reviews Genetics 11(8): 539-548.

Durai, M., Dubey, S. C., \& Tripathi, A. 2012. Genetic diversity analysis and development of SCAR marker for detection of Indian populations of Fusarium oxysporum $\mathrm{f}$. sp. ciceris causing chickpea wilt. Folia Microbiology 57(3): 229-235.

Fraser, C. M. \& Chapple, C. 2011. The phenylpropanoid pathway in Arabidopsis. The Arabidopsis Book / American Society of Plant Biologists 9.

García-Bastidas, F., Ordóñez, N., Konkol, J., Al-Qasim, M., Naser, Z., Abdelwali, M., \& Kema, G. H. J. 2014. First report of Fusarium oxysporum $\mathrm{f}$. sp. cubense tropical race 4 associated with Panama disease of banana outside Southeast Asia. Plant Disease 98(5): 694-694.

Ghag, S. B., Shekhawat, U. K. S., \& Ganapathi, T. R. 2012. Petunia Floral Defensins with unique predominans as novel candidates for development of Fusarium wilt resistance in transgenic banana plants. PLoS ONE 7: e39557.

Ghag, S. B., Shekhawat, U. K. S., \& Ganapathi, T. R. 2014. Transgenic banana plants expressing a Stellaria media defensin gene (Sm-AMP-D1) demonstrate improved resistance to Fusarium oxysporum. Plant Cell Tissue and Organ Culture 119(2): 247-255.

Giberti, S., Bertea, C. M., Narayana, R., Maffei, M. E., \& Forlani, G. 2012. Two phenylalanine ammonia lyase isoforms are involved in the elicitor-induced response of rice to the fungal pathogen Magnaporthe oryzae. Journal of Plant Physiology 169(3): 249-254.

Gübbük, H. \& Pekmezci, M. 2004. In vitro propagation of some new banana types (Musa spp.). Turkish Journal of Agriculture and Forestry 28(5): 355-361.

Guo, L., Han, L., Yang, L., Zeng, H., Fan, D., Zhu, Y., \& Huang, J. 2014. Genome and transcriptome analysis of the fungal pathogen Fusarium oxysporum f. sp. cubense causing banana vascular wilt disease. PLoS One 9 e95543.

Hu, C. H., Wei, Y. R., Huang, Y. H., \& Yi, G. J. 2013. An efficient protocol for the production of chit42 transgenic Furenzhi banana (Musa spp. AA group) resistant to Fusarium oxysporum. In Vitro Cell Development Biology 49(5): 584-592.
International Plant Protection Convention (IPPC). 2013. New banana disease found in Mozambique (Fusarium oxysporum f.sp. cubense Tropical Race 4).

Javed, M. A., Chai, M., \& Othman, R. Y. 2004. Study of resistance of Musa acuminata to Fusarium oxysporum using RAPD markers. Biologia Plantarum 48(1): 93-99.

Kim, S., Cho, Y. J., Song, E. S., Lee, S. H., Kim, J. G., \& Kang, L. W. 2016. Time-resolved pathogenic gene expression analysis of the plant pathogen Xanthomonas oryzae pv. oryzae. BMC Genomics 17(1): 345.

Kim, D. S. \& Hwang, B. K. 2014. An important role of the pepper phenylalanine ammonia-lyase gene (PAL1) in salicylic aciddependent signalling of the defence response to microbial pathogens. Journal of Experimental Botany 65(9): 2295-2306.

Kim, Y.-J., Jang, M.-G., Lee, H.-J., Jang, G.-H., Sukweenadhi, J., Kwon, W.-S, \& Yang, D.-C. 2014. Functional characterization of the pathogenesis-related protein family 10 gene, PgPR10-4, from Panax ginseng in response to environmental stresses. Plant Cell, Tissue and Organ Culture (PCTOC) 118(3): 531-543.

König, S., Feussner, K., Kaever, A., Landesfeind, M., Thurow, C., Karlovsky, P., \& Feussner, I. 2014. Soluble phenylpropanoids are involved in the defense response of Arabidopsis against Verticillium longisporum. New Phytologist 202(3): 823-837.

Li, B., Du, J., Lan, C., Liu, P., Weng, Q., \& Chen, Q. 2013. Development of a loop-mediated isothermal amplification assay for rapid and sensitive detection of Fusarium oxysporum f. sp. cubense race 4. European Journal of Plant Pathology 135(4): 903-911.

Li, C. Y., Deng, G. M., Yang, J., Viljoen, A., Jin, Y., Kuang, R. B., Zuo, C. W., Lv, Z. C., Yang, Q. S., Sheng, O., Wei, Y. R., Hu, C. H., Dong, T., \& Yi, G. J. 2012. Transcriptome profiling of resistant and susceptible Cavendish banana roots following inoculation with Fusarium oxysporum f. sp. cubense tropical race 4. BMC Genomics 13(1):374.

Li, Y., Garibaldi, A., \& Gullino, M. L. 2010. Molecular detection of Fusarium oxysoporum f. sp chrysanthemi on three host plants: Gerbera jamesonii, Osteospermum sp and Argyranthemum frutescens. Journal of Plant Pathology 92: 525-530.

Lin, Y. H., Chang, J. Y., Liu, E. T., Chao, C. P., Huang, J. W., \& Chang, P. F. L. 2009. Development of a molecular marker for specific detection of Fusarium oxysporum f. sp. cubense race 4. European Journal of Plant Pathology 123(3): 353-365.

Lin, Y. H., Chen, K. S., Chang, J. Y., Wan, Y. L., Hsu, C. C., Huang, J. W., \& Chang, P. F. L. 2010. Development of the molecular methods for rapid detection and differentiation of Fusarium oxysporum and F. oxysporum f. sp. niveum in Taiwan. New Biotechnology 27(4): 409-418.

Mahdavi, F., Sariah, M., \& Maziah, M. 2012. Expression of rice thaumatin-like protein gene in transgenic banana plants enhances resistance to Fusarium wilt. Applied Biochemistry and Biotechnology 166(4): 1008-1019.

Mak, C., Mohamed, A. A., Liew, K. W., \& Ho, Y. W. 2001. Early screening technique for Fusarium wilt resistance in banana micropropagated plants. For Proceedings of a meeting held in Leuven, Belgium, 24-28 September 2001, 219-227.

Masheva, S. \& Todorova, V. 2013. Response of pepper varities $F_{1}$ hybrids and breeding lines to Verticillium dablia Kleb in two methods of infestation. Bulgarian Journal of Agricultural Science 19(1): 133-138.

Michelmore, R. 2000. Genomics approaches to plant disease resistance. Current Opinion in Plant Biology 3(2): 125-131.

Mishra, R. K., Pandey, B. K., Muthukumar, M., Pathak, N., \& Zeeshan, M. 2013. Detection of Fusarium wilt pathogens of Psidium guajava $\mathrm{L}$. in soil using culture independent PCR (ciPCR). Saudi Journal of Biological Sciences 20(1): 51-56. 
Mittler, R., Vanderauwera, S., Gollery, M., \& Van Breusegem, F. 2004. Reactive oxygen gene network of plants. Trends in Plant Science 9(10): 490-498.

Moiseyev, G. P., Beintema, J. J., Fedoreyeva, L. I., \& Yakovlev, G. I. 1994. High sequence similarity between a ribonuclease from ginseng calluses and fungus-elicited proteins from parsley indicates that intracellular pathogenesis-related proteins are ribonucleases. Planta 193(3): 470-472.

Muhammad, A. J. \& Othman, R. Y. 2005. Characterization of Fusarium wilt-resistant and Fusarium Wilt-Susceptible somaclones of banana cultivar rastali (Musa AAB) by random amplified polymorphic DNA and retrotransposon. Plant Molecular Biology Reporter 23(3): 241-249.

Munusamy, U., Mohd-Yusuf, Y., Baharum, N. A., Zaidi, K., \& Othman, R. Y. 2019a. RT-qPCR profiling of pathogenesis related genes in Musa acuminata cv.'Berangan' seedlings challenged with Fusarium oxysporum f. sp. cubense Tropical Race 4. Pakistan Journal of Agricultural Sciences 56(1): 37-42

Munusamy, U., Mohd-Yusuf, Y., Zaidi, K., Baharum, N. A., \& Othman, R. Y. 2019b. Evaluation of pathogenicity level of three different strains of Fusarium oxysporum in Musa acuminata cv. Berangan. Research Journal of Biotechnology 14:1220.

O’Neill, W. T., Henderson, J., Pattemore, J. A., O’Dwyer, C., Perry, S., Beasley, D. R., \& Hobbs, R. L. 2016. Detection of Fusarium oxysporum f. sp. cubense tropical race 4 strain in Northern Queensland. Australasian Plant Disease Notes 11(1): 33.

Ordoñez, N., Garcia, F. A., Laghari, H., Akkary, M., Harfouche, E. N., Al Awar, B. N., \& Kema, G. H. 2015. First report of Fusarium oxysporum f. sp. cubense tropical race 4 causing Panama disease in Cavendish bananas in Pakistan and Lebanon. Plant Disease 100(1): 209.

Ortiz, R. \& Swennen, R. 2014. From crossbreeding to biotechnology-facilitated improvement of banana and plantain. Biotechnology Advances 32(1): 158-169.

Pasam, R. K., Sharma, R., Malosetti, M., van Eeuwijk, F. A., Haseneyer, G., Kilian, B., \& Graner, A. 2012. Genomewide association studies for agronomical traits in a worldwide spring barley collection. BMC Plant Biology 12(1): 16.

Paul, J. Y., Becker, D. K., Dickman, M. B., Robert, M. H., Khanna, H. K., \& Dale, J. L. 2011. Apoptosis-related genes confer resistance to Fusarium wilt in transgenic 'Lady Finger' bananas. Plant Biotecbnology Journal 9(9): 1141-1148.

Pegg, K. G., Moore, N. Y., \& Bentley, S. 1996. Fusarium wilt of banana in Australia: A review. Australian Journal of Agricultural Research 47(5): 637-650.

Pérez Vicente, L.F., Dita, M. and Martinez De La Parte, E. 2014. Technical Manual: Prevention and diagnostic of Fusarium Wilt (Panama disease) of banana caused by Fusarium oxysporum f. sp. cubense Tropical Race 4 (TR4). Proceedings of Regional Workshop on the Diagnosis of Fusarium Wilt (Panama disease) caused by Fusarium oxysporum f. sp. cubense Tropical Race 4: Mitigating the Threat and Preventing its Spread in the Caribbean, St. Augustine, Trinidad and Tobago, 05-09/05/2014.FAO, Rome, Italy. 74p.

Pfaffl, M. W. 2004. Relative quantification in: Real-time PCR. Published by International University Line (Editor: T. Dorak), pp. 63-82.

Ploetz, R. C. 2006. Panama disease: An old nemesis rears its ugly head: Part 2. The Cavendish era and beyond. Plant Health Progress 7(1): 36 .

Ploetz, R. C. 2015. Management of Fusarium wilt of banana: A review with special reference to tropical race 4. Crop Protection 73: 7-15.
Rodriguez, H. A., Rodriguez-Arango, E., Morales, J. G., Kema, G., \& Arango, R. E. 2016. Defense gene expression associated with biotrophic phase of Mycosphaerella fijiensis M. Morelet infection in banana. Plant Disease 100(6): 1170-1175.

Rosas-Cárdenas, F. F., Figueroa, N. D., Vielle-Calzada, J. P., CruzHernandez, A., Marsch-Martinez, N., \& De Folter, S. 2011. A simple and efficient method for isolating small RNAs from different plant species. Plant Methods 7(1): 4.

Scarlett, K., Tesoriero, L., Daniel, R., \& Guest, D. 2013. Detection and quantification of Fusarium oxysporum f. sp. cucumerinum in environmental samples using a specific quantitative PCR assay. European Journal of Plant Pathology 137(2): 315-324.

Schmutz, J., McClean, P. E., Mamidi, S., Wu, G. A., Cannon, S. B., Grimwood, J., \& Jackson, S. A. 2014. A reference genome for common bean and genome-wide analysis of dual domestications. Nature Genetics 46(7): 707-713.

Siah, A., Deweer, C., Duyme, F., Sanssené, J., Durand, R., Halama, P., \& Reignault, P. 2010. Correlation of in planta endo-beta1, 4-xylanase activity with the necrotrophic phase of the hemibiotrophic fungus Mycosphaerella graminicola. Plant Pathology 59(4): 661-670.

Soh, H. C., Park, A. R., Park, S., Back, K., Yoon, J. B., Park, H. G., \& Kim, Y. S. 2012. Comparative analysis of pathogenesisrelated protein 10 (PR10) genes between fungal resistant and susceptible peppers. European Journal of Plant Pathology 132(1): 37-48

Subramaniam, S., Maziah, M., Sariah, M., Puad, M. P., \& Xavier, R. 2006. Bioassay method for testing Fusarium wilt disease tolerance in transgenic banana. Scientia Horticulturae 108(4): 378-389.

Thangavelu, R., Perumal, G. D., Mustaffa, M., Sreeramanan, S., \& Rathinam, X. 2012. Genomics of Fusarium oxysporum f. sp. cubense causing wilt disease in banana (Musa spp.) in Genetics, Genomics and Breeding of Bananas. Taylor \& Francis Group.

Van den Berg, N., Berger, D. K., Hein, I., Birch, P. R., Wingfield, M. J., \& Viljoen, A. 2007. Tolerance in banana to Fusarium wilt is associated with early up-regulation of cell wallstrengthening genes in the roots. Molecular Plant Pathology 8(3): 333-341.

Xie, M., Zhang, J., Tschaplinski, T. J., Tuskan, G. A., Chen, J. G., \& Muchero, W. 2018. Regulation of lignin biosynthesis and its role in growth-defense tradeoffs. Frontiers in Plant Science 9: 1427.

Zhang, J., Du, X., Wang, Q., Chen, X., Lv, D., Xu, K., ... \& Zhang, Z. 2010. Expression of pathogenesis related genes in response to salicylic acid, methyl jasmonate and 1aminocyclopropane-1-carboxylic acid in Malus bupehensis (Pamp.) Rehd. BMC Research Notes 3(1): 208.

Zhang, C., Wang, X., Zhang, F., Dong, L., Wu, J., Cheng, Q., \& Li, N. 2017. Phenylalanine ammonia-lyase2. 1 contributes to the soybean response towards Phytophthora sojae infection. Scientific Reports 7(1): 7242. 